\title{
Capitolunate Arthrodesis versus Four-corner Arthrodesis in Scaphoin Nonunion Advanced Collapsed Wrist Treatment
}

\section{Artrodesis lunogrande frente a artrodesis cuatro esquinas en el tratamiento de la muñeca SNAC}

\author{
Sara Alicia González Porto ${ }^{10}$ María Ángeles Cano Leira ${ }^{2 \odot}$ Alba González Rodríguez ${ }^{30}$ \\ Ángel Álvarez Jorge 3 \\ ${ }^{1}$ Departamento de Cirugía Plástica, Hospital POVISA, Vigo, Spain \\ ${ }^{2}$ Departamento de Ortopedia y Traumatología, Hospital Universitario \\ de A Coruña, A Coruña, Spain \\ ${ }^{3}$ Departamento de Cirugía Plástica, Hospital Universitario de A \\ Coruña, A Coruña, Spain \\ Address for correspondence Sara Alicia González Porto, MD, \\ Departamento de Cirugía Plástica, Hospital POVISA, 5 Calle \\ Salamanca. 36211. Vigo, Spain \\ (e-mail: sarali.gonzalezporto@gmail.com; sagonzalez@povisa.es).
}

Rev Iberam Cir Mano 2019;47:32-38.

\begin{abstract}
Objective To evaluate the outcomes of scaphoidectomy and capitolunate arthrodesis versus four-corner arthrodesis in patients with stage III scaphoid nonunion advanced collapse (SNAC) wrists.

Methods We reviewed retrospectively all of the consecutive patients surgically treated in our center between 2007 and 2015, including 20 patients in the four-corner arthrodesis group and 11 patients in the capitolunate group. The mean follow-up time was of 47 months. The follow-up evaluation included wrist range of motion (ROM), grip strength, visual analogue scale (VAS), the disabilities of the arm, shoulder, and hand (DASH) questionnaire, and the Mayo wrist scale (MWS). Postoperative complications and the radiographic evaluation were also assessed.

Keywords

- arthrodesis

- four-corner arthrodesis

- capitolunate

- fusion

- wrist

Results There was no statistical difference in flexion, radial deviation, ulnar deviation, grip strength, VAS, DASH or MWS scores. There was a statistically significant increase $\left(6^{\circ}\right)$ in extension in capitolunate arthrodesis versus four-corner arthrodesis, possibly without clinical relevance. There were two nonunions in the four-corner group, and none in the capitolunate group. None of the patients in the capitolunate group required screw removal. One patient in the four-corner group required dorsal plate removal. One patient in each group required conversion to total arthrodesis.
\end{abstract}

\footnotetext{
(1)Sara Alicia González Porto's ORCID is https://orcid.org/00000003-0285-9110.

(1D) María Ángeles Cano Leira's ORCID is https://orcid.org/00000002-6221-3330.

(D) Alba González Rodríguez's ORCID is https://orcid.org/0000-00032618-2562.
}

received

January 28, 2019

accepted

March 25, 2019
DOI https://doi.org/

10.1055/s-0039-1688971. ISSN 1698-8396.
Copyright $\odot 2019$ Thieme Revinter

Publicações Ltda, Rio de Janeiro, Brazil
License terms

(c) $(1) \$$ 


\section{Resumen}

\author{
Palabras clave \\ - artrodesis \\ - artrodesis cuatro \\ esquinas \\ - lunogrande \\ - fusión \\ - muñeca
}

Conclusions Capitolunate arthrodesis shows similar results in wrist ROM, grip strength and patient-reported outcomes when compared with four-corner arthrodesis at an average follow-up period of 4 years. We did not have any pisotriquetral arthritis in the capitolunate arthrodesis group, despite not removing the triquetrum in any of patients of this group.

Type of study/level of evidence Therapeutic III.

Objetivo Evaluar los resultados de la escafoidectomía y de la artrodesis lunogrande frente a la artrodesis cuatro esquinas en pacientes con muñecas SNAC (Scaphoid Nonunion Advanced Collapse) estadío III.

Métodos Evaluamos retrospectivamente todos los pacientes intervenidos quirúrgicamente en nuestro centro de forma sucesiva entre 2007 y 2015 , incluyendo 20 pacientes en el grupo de la artrodesis cuatro esquinas y 11 pacientes en el grupo de la artrodesis lunogrande. El seguimiento medio fue de 47 meses. El seguimiento incluyó la evaluación del rango de movimiento de la muñeca, la fuerza de agarre, la escala analógica visual (VAS), el cuestionario de discapacidades del brazo, hombro y mano (DASH), y la escala de muñeca de Mayo (MWS). También se valoraron las complicaciones postoperatorias y las pruebas de imagen solicitadas.

Resultados No hubo diferencias estadísticamente significativas en la flexión, desviación radial, desviación ulnar, fuerza de agarre, ni en las escalas VAS, DASH o MWS. Se evidenció un incremento estadísticamente significativo (seis grados) en la extensión en el grupo de la artrodesis lunogrande frente a la artrodesis cuatro esquinas, posiblemente sin relevancia clínica asociada. Se registraron dos no uniones en el grupo de la artrodesis cuatro esquinas, y ningún caso en el grupo de la artrodesis lunogrande. Ninguno de los pacientes en el grupo de la artrodesis lunogrande requirió la retirada del tornillo. Un paciente en el grupo de la artrodesis cuatro esquinas precisó de la retirada de la placa dorsal. Un paciente de cada grupo requirió la conversión a artrodesis total de muñeca.

Conclusiones La artrodesis lunogrande muestra resultados similares en rango de movimiento de la muñeca, fuerza de agarre y satisfacción percibida por el paciente respecto a la artrodesis cuatro esquinas con un seguimiento medio de cuatro años. No hubo ningún caso de artrosis piramido-pisiforme a pesar de no haber eliminado el piramidal en ninguno de los pacientes.

Tipo de estudio/nivel de evidencia Terapéutico III.

\section{Introduction}

Motion-sparing surgical treatment of advanced degenerative osteoarthritis of the wrist, secondary to a long standing scaphoid nonunion (scaphoid nonunion advanced collapse [SNAC] wrists), consists of scaphoidectomy and a midcarpal fusion to stabilize the midcarpal joint and to avoid the proximal migration of the capitate, or proximal row carpectomy. ${ }^{1}$ The compromise of the head of the capitate (stage III) prevents the use of proximal row carpectomy, and the partial carpal fusions most commonly used are four-corner arthrodesis and capitolunate arthrodesis, with or without excision of the triquetrum. ${ }^{2}$

Graner first described capitolunate arthrodesis in 1966 for the treatment of Kienböck disease. ${ }^{3}$ In 1984, Watson described capitolunate arthrodesis and four-corner arthrodesis for the treatment of scapholunate advanced collapse (SLAC) wrists. ${ }^{4}$ In the original paper by Watson, 3 of the 16 patients underwent a capitolunate arthrodesis, with similar results in the 13 patients who underwent a four-corner arthrodesis. However, despite good outcomes, this technique was discouraged for the treatment of SLAC or SNAC wrists due to its high nonunion rate. $^{5}$

After the introduction of compression screws as fixation hardware, the incidence of reported nonunion has decreased. ${ }^{6}$ Other advantages, such as a lesser need for bone grafting, have brought attention to capitolunate arthrodesis as an alternative to four-corner arthrodesis.

Although Gaston et al reported a retrospective series of capitolunate arthrodesis and compared it to four-corner arthrodesis, they used two antegrade lunocapitate compression screws and the triquetrum was excised in the majority of the cases, ${ }^{7}$ as in the series presented by Calandruccio. ${ }^{2}$

To the best of our knowledge, no case series of capitolunate arthrodesis with only one antegrade screw have been reported.

The purpose of the present study is to evaluate the outcomes of scaphoidectomy and capitolunate arthrodesis 
versus four-corner arthrodesis in patients with stage III SNAC wrists, using one antegrade compression screw, and without performing excision of the triquetrum in the capitolunate arthrodesis.

\section{Methods}

After approval of the present study from the institutional review board, 32 patients with SNAC III wrists surgically treated from 2007 to 2015 were identified retrospectively (20 patients who underwent four-corner arthrodesis, and 12 patients who underwent capitolunate arthrodesis). All of the patients with SLAC wrists were excluded, and those with SNAC wrists who had not undergone any of the stated techniques, and/or with radiolunate compromise or ulnar translocation of the wrist, were excluded. One of the patients of the capitolunate arthrodesis group was excluded due to inability to complete the follow-up protocol. The remaining 31 patients agreed to participate and were able to complete the follow-up. Of these, 11 underwent capitolunate arthrodesis, and 20 underwent four-corner arthrodesis.

The mean follow-up period of all of the patients was 46.8 months, with a range between 19 and 97 months. The mean follow-up period of the four-corner arthrodesis and capitolunate arthrodesis was of 49.5 months and of 41.9 months, respectively. There were no statistically significant differences between the mean follow-up periods ( $p=0.2$ ).

In - Table 1, the demographics of the patients are shown. There were no significant differences in terms of age or of high-demand percentage of patients.

Hand therapists, blinded to the procedure performed, evaluated the postoperative wrist ranges of motion (ROMs) and grip strength. The postoperative outcomes of the patients were measured through three subjective outcome scales: the visual analog scale (VAS), the disabilities of the arm, shoulder, and hand (DASH) score, and the Mayo wrist score (MWS). All of the postoperative complications, such as nonunion, hardware-related problems, and conversion to wrist arthrodesis or to arthroplasty were recorded. Nonunion was defined as the

Table 1 Demographics of four-corner arthrodesis and capitolunate groups of patients

\begin{tabular}{|l|l|l|l|}
\hline Features & $\begin{array}{l}\text { Four-corner } \\
\text { arthrodesis }\end{array}$ & $\begin{array}{l}\text { Capitolunate } \\
\text { arthrodesis }\end{array}$ & $p$-value \\
\hline $\begin{array}{l}\text { Mean age } \\
\text { (years old) }\end{array}$ & $46.5(12.6)$ & $40.54(11.5)$ & 0.298 \\
\hline $\begin{array}{l}\text { Percentage of } \\
\text { male gender }\end{array}$ & $85 \%$ & $81.8 \%$ & - \\
\hline $\begin{array}{l}\text { Percentage of } \\
\text { right-handed }\end{array}$ & $90 \%$ & $100 \%$ & - \\
\hline $\begin{array}{l}\text { Percentage of } \\
\text { right-sided } \\
\text { injuries }\end{array}$ & $60 \%$ & $66.7 \%$ & - \\
\hline High demand & $66.7 \%$ & $63 \%$ & 0.868 \\
\hline Preoperative VAS* & $4.2(0.4)$ & $3.2(1.0)$ & 0.012 \\
\hline
\end{tabular}

Abbreviation: VAS, visual analogue scale.

${ }^{*}$ Age and VAS are expressed as mean (standard deviation). absence of bony consolidation on the radiographic evaluation, with or without the presence of tenderness over the arthrodesis site on the physical examination. In case any patient presented radiographic images consistent with nonunion, the diagnosis was confirmed by a computed tomography (CT) scan.

A descriptive analysis of all of the variables included was performed, expressing qualitative variables in absolute values and in percentages; and quantitative variables as mean and standard deviation (SD), along with 95\% confidence intervals (CIs).

The statistical analysis was performed using the MannWhitney test and the Fisher exact test with IBM SPSS Statistics for Windows, Version 19.0 (IBM Corp., Armonk, NY, USA).

The dorsal wrist approach consisted of a longitudinal incision on the skin, of the opening of the fourth extensor compartment, and of the opening of the dorsal capsule using a longitudinal incision. After the scaphoidectomy and of the removal of the cartilage of the involved joints, the dorsal intercalated segmental instability (DISI) deformity, if present, was corrected and the capitolunate fusion was performed using a single antegrade headless Newclip Handmotion compression screw (Newclip Technics, Nantes, France) (-Fig. 1). The triquetrum was not

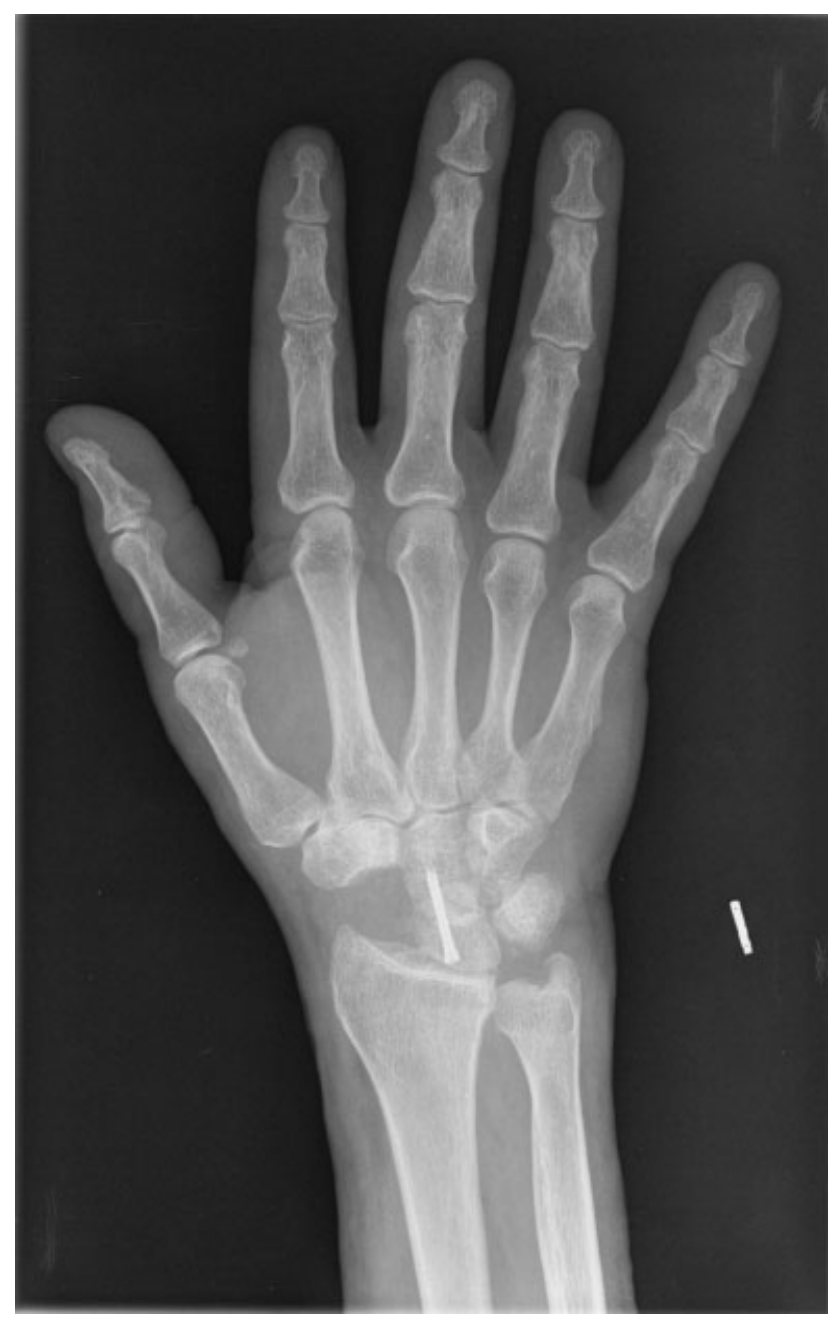

Fig. 1 Capitolunate arthrodesis. Posteroanterior X-ray showing capitolunate arthrodesis with a antegrade compression screw in a patient with scaphoid nonunion advanced collapse wrist 5 months postoperatively. 
excised in any of the patients. Bone grafts from the scaphoidectomy were used in 7 patients. Additional radial styloidectomy was performed in 5 patients, and posterior interosseous neurectomy in 7 patients. The criteria to perform the posterior interosseous neurectomy depended on the preoperative pain reported by the patient, being performed on those patients with intense pain in their SNAC wrist.

The four-corner arthrodesis was performed using the same approach. The fusion of the lunate, capitate, hamate and triquetrum bones was performed using staples ( 3 patients), a dorsal Spider plate (Smith \& Nephew, London, UK) (8 patients), or headless Newclip Handmotion compression screws (9 patients) ( - Fig. 2 ). Bone grafts from the scaphoidectomy were used in all of the patients. Additional radial styloidectomy was performed in 4 patients, and posterior interosseous neurectomy in 18 patients.

Postoperative splinting for between 3 and 4 weeks was mandatory in all of the cases that used screws for bony fusion. In patients with dorsal plate, the splint was used for 6 weeks, and in patients with staples, for between 7 and 8 weeks.

All the patients attended routinely to therapy and activeassisted range of motion (ROM) exercise was started just after the splint was removed. Passive ROM exercise was initiated at 8 weeks postoperatively, unless there was ten-

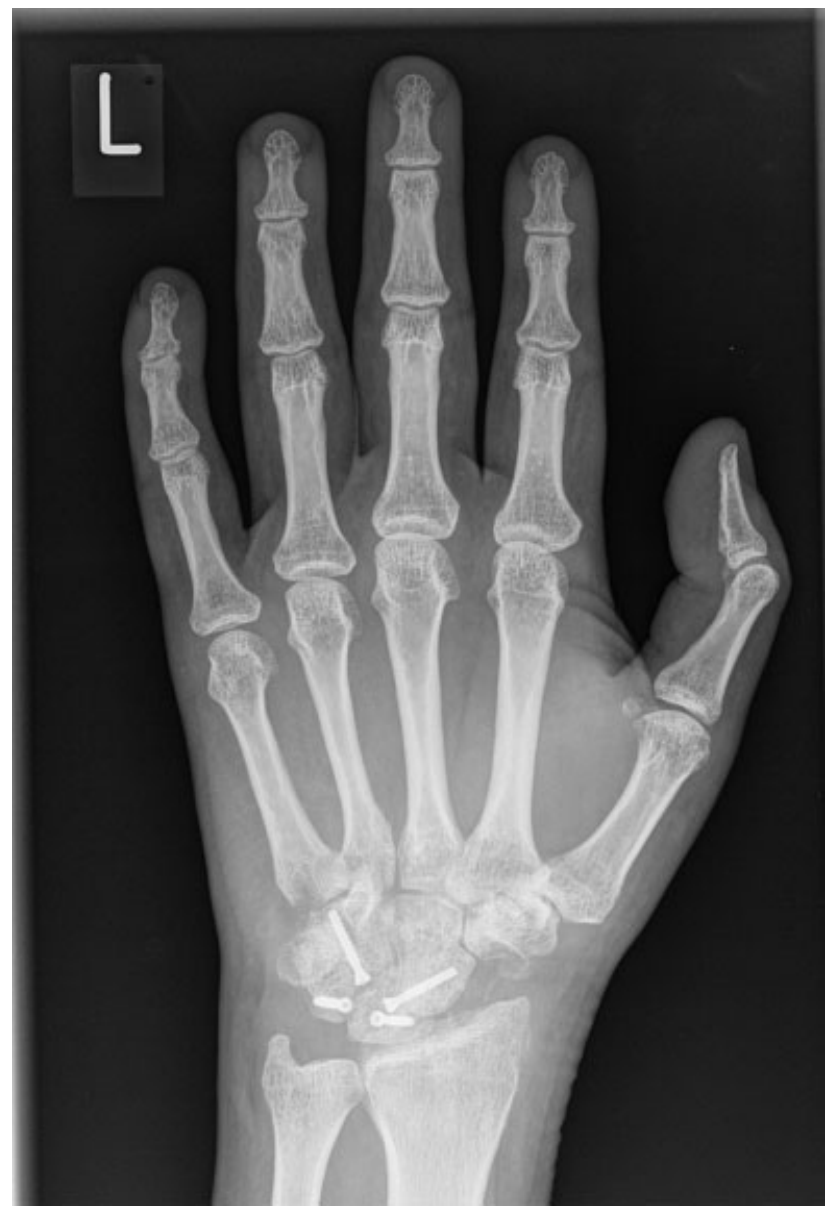

Fig. 2 Four-corner arthrodesis with a dorsal plate. Posteroanterior $X$-ray showing four-corner arhtrodesis with a dorsal plate in a patient with scaphoid nonunion advanced collapse wrist 3 months postoperatively.
Table 2 Results* of wrist functionality and outcome scales

\begin{tabular}{|l|l|l|l|}
\hline & $\begin{array}{l}\text { Four-corner } \\
\text { arthrodesis }\end{array}$ & $\begin{array}{l}\text { Capitolunate } \\
\text { arthrodesis }\end{array}$ & $p$-value \\
\hline VAS & $1.5(0.8)$ & $1.4(1.3)$ & 0.774 \\
\hline DASH & $35.1(17.3)$ & $48.1(33.1)$ & 0.256 \\
\hline MWS & $61.6(20.7)$ & $54.5(29.3)$ & 0.296 \\
\hline Flexion & $37.5^{\circ}\left(12.1^{\circ}\right)$ & $38.7^{\circ}\left(9^{\circ}\right)$ & 0.877 \\
\hline Extension & $27.3^{\circ}\left(12.9^{\circ}\right)$ & $33.1^{\circ}\left(12.3^{\circ}\right)$ & 0.031 \\
\hline Radial deviation & $13.1^{\circ}\left(7.6^{\circ}\right)$ & $14.5^{\circ}\left(4.6^{\circ}\right)$ & 0.674 \\
\hline Ulnar deviation & $20^{\circ}\left(8.4^{\circ}\right)$ & $19.3^{\circ}\left(10.2^{\circ}\right)$ & 0.912 \\
\hline Grip strength & $\begin{array}{l}30.5 \mathrm{~kg} \\
(28.9 \mathrm{~kg})\end{array}$ & $\begin{array}{l}19.8 \mathrm{~kg} \\
\left(24 . \mathrm{kg}^{\circ}\right.\end{array}$ & 0.296 \\
\hline
\end{tabular}

Abbreviations: DASH, disabilities of the arm, shoulder, and hand questionnaire; MWS, Mayo wrist scale; VAS, visual analogue scale. *Results are shown as mean (standard deviation).

derness over the arthrodesis site or there was no evidence of radiographic bone healing.

\section{Results}

The functional outcome is summarized in -Tables $\mathbf{2}$ and $\mathbf{3}$. There were no statistically significant differences between the groups in VAS, DASH or MWS, ROM or grip strength.

The mean flexion-extension arc was $52.3 \%$ of the contralateral side for four-corner arthrodesis, and $55.2 \%$ of the contralateral side for capitolunate arthrodesis. This difference of $2.9 \%$ in flexion-extension means was not statistically significant $(p=0.145)$.

The radioulnar deviation arc averaged $41.4 \%$ of the contralateral side for four-corner arthrodesis, and $51.1 \%$ of the contralateral side for capitolunate patients. The mean difference of $9.7 \%$ between the 2 techniques was not statistically significant $(p=0.066)$.

The mean pronation-supination arc was $96.8 \%$ of the contralateral side for four-corner arthrodesis, and $98 \%$ of

Table 3 Functional outcome*

\begin{tabular}{|l|l|l|l|}
\hline & $\begin{array}{l}\text { Four-corner } \\
\text { arthrodesis }\end{array}$ & $\begin{array}{l}\text { Capitolunate } \\
\text { arthrodesis }\end{array}$ & $p$-value \\
\hline Flexion & $58.6 \%(24.2)$ & $61.4 \%(19.7)$ & 0.359 \\
\hline Extension & $50.0 \%(36.6)$ & $65.7 \%(17.0)$ & 0.060 \\
\hline Radial deviation & $38.4 \%(22.3)$ & $59.1 \%(39.4)$ & 0.183 \\
\hline Ulnar deviation & $44.5 \%(28.6)$ & $46.2 \%(12.3)$ & 0.583 \\
\hline Grip strength & $62.51 \%(33.5)$ & $58.7 \%(26.9)$ & 0.133 \\
\hline $\begin{array}{l}\text { Flexion-extension } \\
\text { arc }\end{array}$ & $52.3 \%(22.2)$ & $55.2 \%(13.9)$ & 0.145 \\
\hline $\begin{array}{l}\text { Radioulnar } \\
\text { deviation arc }\end{array}$ & $41.4 \%(21.9)$ & $51.1 \%(9.6)$ & 0.066 \\
\hline Pronosupination & $96.8 \%(0.8)$ & $98 \%(1.3)$ & 0.124 \\
\hline
\end{tabular}

*Results are expressed as a percentage (standard deviation). The percentages result from the comparison with the contralateral side of the injury. 
the contralateral side for capitolunate arthrodesis. This difference of $1.2 \%$ was not statistically significant ( $p=0.124$ ).

The mean grip strength was $62.5 \%$ of the contralateral side for four-corner arthrodesis, and $58.7 \%$ of the contralateral side for capitolunate arthrodesis. This difference of 3.8\% was not statistically significant $(p=0.133)$.

Bone graft was needed in 7 patients of the capitolunate arthrodesis group (63.6\%), and in all of the patients of the fourcorner arthrodesis group (100\%). The donor site of the bone graft was always the scaphoid bone from the scaphoidectomy.

Two patients in the four-corner arthrodesis group (10\%), with a dorsal plate used as the fixation hardware, presented with nonunion, compared with none in the capitolunate arthrodesis group ( $0 \%)$, and this difference was not statistically significant $(p=0.409)$.

One patient in the four-corner arthrodesis group required removal of the dorsal plate and tenolysis of the extensor tendons.

One patient in the four-corner arthrodesis group underwent a revision to total wrist arthrodesis. The method of fixation used in the four-corner arthrodesis had been a dorsal plate. One of the patients in the capitolunate arthrodesis group converted to total wrist arthrodesis. None of the patients were revised to wrist arthroplasty.

\section{Discussion}

The present study found similar outcomes for four-corner arthrodesis and capitolunate arthrodesis in patients with stage III SNAC wrists, using one antegrade compression screw, and without performing excision of the triquetrum in the capitolunate arthrodesis. These results are comparable to the findings of the recent literature on the subject. ${ }^{7}$

One of the remaining concerns about capitolunate arthrodesis is the long-term results. The follow-up periods of the series of Kirschenbaum et al, ${ }^{8}$ Calandruccio et al, ${ }^{2}$ Goubier et $\mathrm{al}^{6}{ }^{6}$ Hegazy, ${ }^{9}$ and of Gaston et al $^{7}$ are of 36, 28, 29, 37, and 31 months, respectively. Durand et al reported a series with 4 years of follow-up, ${ }^{10}$ the same as in the present study, and Krakauer et al followed-up 8 patients for 50 months. ${ }^{11}$ The study presented by Delclaux et al followed-up 12 patients with capitolunate arthrodesis for 10 years. ${ }^{12}$

Another concern might be the small number of patients included on the aforementioned series, which ranges from 8 to 20 patients, and might limit the power of the statistical analysis to obtain significant differences when comparing capitolunate arthrodesis with other techniques.

Regarding the functional outcome, and despite the fact that there were no significant differences between the groups in flexion-extension, radioulnar deviation, or pronation-supination arcs in our series, capitolunate arthrodesis achieved a greater ROM. The almost $10 \%$ difference in radioulnar deviation between the 2 techniques was not statistically significant $(p=0.066)$, but it may have clinical relevance. The ROM for capitolunate arthrodesis patients is similar to the reported ROM in previous series.

However, the grip strength was better for the four-corner arthrodesis group (62.5\% of the contralateral side versus
58.7\% for capitolunate arthrodesis), despite no significant differences having been observed. In our series, the grip strength for capitolunate arthrodesis (58.7\%) was slightly lower than the reported in other series (60-80\%).

Despite the fact that a bone graft was only harvested in 7 patients of capitolunate fusion, no nonunions were found. However, the bone graft was harvested from the scaphoidectomy in all of the patients of four-corner arthrodesis, and two patients presented with nonunion. It must be noted that, in both cases of nonunion, the fixation hardware was a Spider dorsal plate, which has been related to high nonunion rates of up to $62 \%$ in four-corner arthrodesis. ${ }^{13,14}$ The fusion was also performed with a Spider dorsal plate in the case requiring tenolysis and in the case converted to total wrist arthrodesis. None of the cases of four-corner arthrodesis in which compression screws or staples were used for fixation presented with nonunion.

One important limitation of the present study is the retrospective nature of the review. This means that a possible selection bias would only be addressed in a prospective randomized study. Other limitations are the small sample size, especially in the lunocapitate group, which can be noted by the large SDs of the collected data, the lack of preoperative data for comparison, the different techniques used in the four-corner arthrodesis group, and also by the addition of posterior interosseous neurectomy and styloidectomy in different percentages in the four-corner arthrodesis group versus the capitolunate arthrodesis group, which could bias the overall results.

Despite these limitations, we present our technique for capitolunate arthrodesis with one antegrade compression screw as a possible alternative to four-corner arthrodesis, which has the advantages of reducing operative time and fixation hardware costs. In addition, the nonunion rate in the present study is comparable to that of the study of Gaston et $\mathrm{al}^{7}$ who proposed the use of two antegrade compression screws.

Four-corner wrist arthrodesis is the classic method for the treatment of SNAC III wrists over capitolunate arthrodesis due to the higher surface of bony union and, as a consequence, to the lower expected nonunion rate. In addition, the concern about proximal migration of the screws or progression of radiolunate degeneration in the capitolunate arthrodesis makes the outcomes of this technique more unpredictable than performing the endorsed four-corner arthrodesis. ${ }^{15}$ However, the recent literature reports similar outcomes of capitolunate arthrodesis versus four-corner arthrodesis. Contraindications for this technique are radiolunate compromise and ulnar translocation of the wrist. ${ }^{9}$

The main complications of four-corner arthrodesis are nonunion (5.5\%), hardware-related complications (3.3\%), and dorsal impingement or lunate malposition (2.6\%). ${ }^{9-12}$ The complications may be related to the surgical technique, to the quality of the bone grafting, and to the fixation hardware used. Consequently, the literature demonstrates variable nonunion rates in a series of four-corner arthrodesis performed with dorsal plate. ${ }^{13}$

The reported long-term results are a flexion-extension of $55 \%$ of the contralateral side, grip strength of $80 \%$ of the 
contralateral side, and absence of pain in between 80 and $90 \%$ of the patients. ${ }^{9,13,14,16}$

The method of internal fixation described for four-corner arthrodesis involves Kirschner wires, staples, screws and dorsal plates. The nonunion rate for the $1^{\text {st }} 3$ methods of fixation ranges from 3 to $18 \%$, and in the case of dorsal plates, from 16 to $62 \%{ }^{16-18}$ Headless compression screws are the recommended method for fixation in four-corner arthrodesis. $^{7}$

Since the original capitolunate technique was reported by Watson, ${ }^{4}$ and despite the need of less bony graft compared with four-corner arthrodesis, the initial reported nonunion rates associated with this procedure ranged from 33 to $50 \%$ with Kirschner wires or staples. ${ }^{19}$ Since the introduction of compression screws, the reported nonunion rates were drastically reduced, reaching $8 \%$ in the series reported by Goubier et $\mathrm{al}^{6}$ and by Delclaux et $\mathrm{al}^{12}$ and $0 \%$ in the series reported by Gaston et al and by Hegazy. ${ }^{7,9}$ In addition, a shorter operative time and less dissection of the soft tissue make this procedure an appealing alternative to four-corner arthrodesis. $^{19}$

Regarding the functional outcome in capitolunate arthrodesis, flexion-extension was reported to range between 48 and $53 \%$ of the contralateral side, and the grip strength from 61 to $70 \% 8,18$

Some technical refinements have been proposed, such as excision of the triquetrum to avoid ulnar impaction, although increasing radiolunate contact. ${ }^{8,18}$ Excision of the triquetrum was also reported in type II lunate, to avoid pisotriquetral arthritis and to ease lunate reduction. ${ }^{4}$ However, Ferreres et al established the importance of the preservation of the lunotriquetral joint to maintain proprioception of the radiotriquetral ligaments. ${ }^{1}$

When treating the degenerative arthritis that follows scapholunate instability or scaphoid pseudarthrosis, excision of the scaphoid must be combined with a stabilization of the midcarpal joint. Two alternatives have been proposed for that purpose: fusing the lunate, the triquetrum, the capitate, and the hamate bones (four-corner fusion) or limiting the arthrodesis to the lunate and capitate bones, preserving or excising the triquetrum. Previous reports have attributed a high level of complications to lunocapitate arthrodesis, mainly regarding nonunion. We have reviewed 11 patients who had been treated with a lunocapitate fusion, with no removal of the triquetrum, after a 4-year follow-up period, and found similar results compared with four-corner arthrodesis, even with a major degree of motion in ulnar-radial deviation. A recent work on the innervation of the radiotriquetral ligaments has given relevance to the preservation of lunotriquetral motion in maintaining proprioception. Also, if the triquetrum is excised to gain more motion, the proprioceptive role of the radiotriquetral ligaments is compromised.

Even so, there is no randomly designed study to evaluate four-corner arthrodesis and capitolunate arthrodesis in SNAC or SLAC wrists. The risk of bias in the evaluation of capitolunate arthrodesis is based on the possibility of reserving the usage of capitolunate arthrodesis to those patients with better bone stock and less risk of developing nonunion based on the preoperative evaluation of the patient and on the experience of the surgeon. In addition, the differences in the immobilization protocol between groups could also affect the results.

\section{Conclusions}

Capitolunate arthrodesis remains an acceptable alternative to four-corner arthrodesis as far as nonunion and postoperative complications in the short-term follow-up are concerned. However, long-term prospective randomized studies are needed to compare this technique with four-corner arthrodesis before capitolunate arthrodesis can be considered a gold standard in the treatment of wrist osteoarthritis.

Conflicts of Interests

The authors have no conflicts of interests to declare.

\section{Acknowledgment}

We would like to thank Samuel H. E. Chu for the review of the transcription of the manuscript.

\section{References}

1 Ferreres A, Garcia-Elias M, Plaza R. Long-term results of lunocapitate arthrodesis with scaphoid excision for SLAC and SNAC wrists. J Hand Surg Eur Vol 2009;34(05):603-608

2 Calandruccio JH, Gelberman RH, Duncan SF, Goldfarb CA, Pae R, Gramig W. Capitolunate arthrodesis with scaphoid and triquetrum excision. J Hand Surg Am 2000;25(05):824-832

3 Graner O, Lopes EI, Carvalho BC, Atlas S. Arthrodesis of the carpal bones in the treatment of Kienböck's disease, painful ununited fractures of the navicular and lunate bones with avascular necrosis, and old fracture-dislocations of carpal bones. J Bone Joint Surg Am 1966;48(04):767-774

4 Watson HK, Ballet FL. The SLAC wrist: scapholunate advanced collapse pattern of degenerative arthritis. J Hand Surg Am 1984;9 (03):358-365

5 Siegel JM, Ruby LK. A critical look at intercarpal arthrodesis: review of the literature. J Hand Surg Am 1996;21(04):717-723

6 Goubier JN, Teboul F. Capitolunate arthrodesis with compression screws. Tech Hand Up Extrem Surg 2007;11(01):24-28

7 Gaston RG, Greenberg JA, Baltera RM, Mih A, Hastings H. Clinical outcomes of scaphoid and triquetral excision with capitolunate arthrodesis versus scaphoid excision and four-corner arthrodesis. J Hand Surg Am 2009;34(08):1407-1412

8 Kirschenbaum D, Schneider LH, Kirkpatrick WH, Adams DC, Cody RP. Scaphoid excision and capitolunate arthrodesis for radioscaphoid arthritis. J Hand Surg Am 1993;18(05):780-785

9 Hegazy G. Capitolunate Arthrodesis for Treatment of Scaphoid Nonunion Advanced Collapse (SNAC) Wrist Arthritis. J Hand Microsurg 2015;7(01):79-86

10 Durand A, Harisboure A, Nurbel B, et al. [Capitolunate arthrodesis with tension band wire in wrist arthritis: twenty cases with four year follow-up]. Rev Chir Orthop Repar Appar Mot 2007;93(01): 37-45

11 Krakauer JD, Bishop AT, Cooney WP. Surgical treatment of scapholunate advanced collapse. J Hand Surg Am 1994;19(05): 751-759

12 Delclaux S, Rongières M, Aprédoaei C, Bonnevialle N, Bonnevialle P, Mansat P. [Capitolunate arthrodesis: 12 patients followed-up an average of 10 years]. Chir Main 2013;32(05):310-316 
38 Capitolunate Arthrodesis...is it Worth it? González Porto et al.

13 Kendall CB, Brown TR, Millon SJ, Rudisill LE Jr, Sanders JL, Tanner SL. Results of four-corner arthrodesis using dorsal circular plate fixation. J Hand Surg Am 2005;30(05):903-907

14 Rudnick B, Goljan P, Pruzansky JS, Bachoura A, Jacoby SM, Rekant MS. Four-corner arthrodesis with a radiolucent locking dorsal circular plate: technique and outcomes. Hand (N Y) 2014;9(03): 315-321

15 Shifflett GD, Athanasian EA, Lee SK, Weiland AJ, Wolfe SW. Proximal migration of hardware in patients undergoing midcarpal fusion with headless compression screws. J Wrist Surg 2014;3 (04):250-261
16 Vance MC, Hernandez JD, Didonna ML, Stern PJ. Complications and outcome of four-corner arthrodesis: circular plate fixation versus traditional techniques. J Hand Surg Am 2005;30(06):1122-1127

17 Rhee PC, Kakar S, Shin AY. Four-corner arthrodesis with a locking, dorsal circular polyether-ether-ketone (PEEK-Optima) plate. Tech Hand Up Extrem Surg 2012;16(04):236-241

18 Shin AY. Four-corner arthrodesis. J Am Soc Surg Hand 2001; 1:93-111

19 Ronchetti PJ, Topper SM. Lunocapitate fusion using the OSStaple compression staple. Tech Hand Up Extrem Surg 2006;10(04): 231-234 